\title{
In situ protocol for the determination of dose- response effect of low-fluoride dentifrices on enamel remineralization
}

\author{
Rebeca Lima AFONSO, Juliano Pelim PESSAN, Bruna Babler IGREJA, Camila Fernandes CANTAGALLO, Marcelle \\ DANELON, Alberto Carlos Botazzo DELBEM
}

Department of Pediatric Dentistry and Public Health, Araçatuba Dental School, Univ. Estadual Paulista (UNESP), Araçatuba, SP, Brazil.

\begin{abstract}
Corresponding address: Alberto Carlos Botazzo Delbem - Departamento de Odontologia Infantil e Social - Faculdade de Odontologia de Araçatuba - Univ. Estadual Paulista (UNESP) - Rua José Bonifácio 1193 - 16015-050 - Araçatuba - SP - Brazil - Phone: +55 1836363314 - Fax +55 1836363332 - e-mail: adelbem@foa.unesp.br - adelbem@pq.cnpq.br
\end{abstract}

Submitted: April 25, 2013 - Accepted: August 29, 2013

ABSTRACT

No in situ protocol has assessed the dose-response effects of fluoride dentifrices involving low-fluoride formulations. Objective: To assess the ability of an in situ remineralization model in determining dose-response effects of dentifrices containing low fluoride concentrations ([F]) on bovine enamel. Material and Methods: Volunteers wore palatal appliances containing demineralized enamel blocks and brushed their teeth and devices with the dentifrices supplied (double-blind, crossover protocol) separately for 3 and 7 days. Surface hardness $(\mathrm{SH})$, integrated subsurface hardness $(\triangle \mathrm{KHN})$ and $[\mathrm{F}]$ in enamel were determined. Data were analyzed by ANOVA, Tukey's test and Pearson's correlation $(p<0.05)$. Results: Dose-response relationships were verified between $[F]$ in dentifrices and $\mathrm{SH}, \triangle \mathrm{KHN}$ and enamel $[\mathrm{F}]$. Higher correlation coefficients between enamel [F] and $\mathrm{SH}$ and $\triangle \mathrm{KHN}$ were obtained for the 3-day period. Significant differences in $\mathrm{SH}$ and $\triangle \mathrm{KHN}$ were observed among all groups for the 3-day period, but not between 0-275, 275-550, and 550-1,100 $\mu \mathrm{g} \mathrm{F/g}$ dentifrices for the 7-day period, nor between 3- and 7-day periods for the $1,100 \mu \mathrm{g} / \mathrm{g}$ groups. Conclusions: Considering that the peak remineralization capacity of the conventional dentifrice $(1,100 \mu \mathrm{g} / \mathrm{g})$ was achieved in 3 days, this experimental period could be used in future studies assessing new dentifrice formulations, especially at low-fluoride concentrations.

Key words: Dentifrices. Dental enamel. Fluorides. Tooth remineralization.

\section{INTRODUCTION}

Throughout the $20^{\text {th }}$ century, fluoride was the main agent used for the control of dental caries worldwide, being available to the population through the use of vehicles of varying concentrations and modes of use. Studies carried out in different countries indicate the use of fluoride-containing dentifrices as the main responsible for both the decrease in caries prevalence and the increase in dental fluorosis ${ }^{24,29}$. Among the strategies to decrease fluoride intake from this source, and therefore minimizing the risk to develop dental fluorosis, the reduction of fluoride concentration in dentifrices used by young children has been proposed ${ }^{15}$. Considering the controversies surrounding the efficacy of low-fluoride dentifrices when compared to conventional formulations ${ }^{3,27}$, alternatives to improve their efficacy have been tested in vitro, which include low-pH formulations ${ }^{2}$ and the supplementation with phosphate salts ${ }^{25}$. In order to further confirm these findings, however, in situ tests should be conducted to verify the dentifrice capacity to reduce mineral loss and/or enhance remineralization prior to clinical trials, which are more costly and time demanding.

A variety of in situ protocols assessing the remineralizing capacity of fluoride dentifrices, solutions and gels is described in the literature. Most of the studies, however, evaluated products containing high fluoride concentrations ${ }^{1,16}$, while others compared low-fluoride products with different remineralizing agents $8,19,22,25$ or only 
with placebo treatment ${ }^{4,9}$. According to recent recommendations, in situ protocol designs must determine dose-response effects in order to attest the efficacy of already existing formulations, as well as to validate new formulations ${ }^{3}$. Nevertheless, when developing and evaluating low-fluoride dentifrices, it is difficult to select a protocol that fulfills the above-mentioned recommendations, as existing protocols vary considerably regarding the length of experimental period ( 7 to 60 days), substrate (human or bovine enamel), treatment frequency ( 2 to 4 times/day), and whether the application is in vivo or ex vivo. Moreover, no protocol has assessed differences between groups regarding variation in fluoride concentration.

Since no in situ protocol has assessed the doseresponse effects of fluoride dentifrices, especially involving low-fluoride dentifrices, the aim of this study was to evaluate an in situ remineralization model in order to determine dose-response effects with dentifrices containing low fluoride concentrations using artificially demineralized bovine enamel.

\section{MATERIAL AND METHODS}

\section{Study design}

This study followed a double-blind, crossover protocol, assessing the effect of 4 different treatments (dentifrices containing 0, 275, 550 and $1,100 \mu \mathrm{g} \mathrm{F} / \mathrm{g}$, as $\mathrm{NaF}$ ), tested separately for 3 and 7 days. Bovine enamel blocks $(3 \times 3$ $\mathrm{mm}, n=330$ ) selected by surface hardness (SH) were artificially demineralized, and subsequently submitted to post demineralization hardness test $\left(\mathrm{SH}_{1}\right)$. Ten blocks were also analyzed by polarized light microscopy prior to the in situ phases. Sample size was established at 9 volunteers per group to obtain a power of $80 \%(a=0.05)$, based on a previous study conducted with similar research protocol ${ }^{11}$. Considering the possibility of dropouts, 12 volunteers were included in the study. During each experimental phase, volunteers wore palatal appliances containing 4 demineralized enamel blocks and were randomly assigned to 1 of the 8 possible treatments. They were instructed to brush their teeth and the palatal devices with the dentifrices supplied ( 3 times/day); a fluoridefree dentifrice was used by the volunteers for 7 days between each experimental phase. Surface $\left(\mathrm{SH}_{2}\right)$ and cross-sectional hardness were assessed to calculate the percentage of surface hardness recovery $(\% \mathrm{SH})$ and integrated subsurface hardness $(\triangle \mathrm{KHN})$, respectively. Fluoride concentration in enamel was also determined. Dentifrices and experimental periods were considered as variation factors, and surface hardness $\left(\mathrm{SH}, \mathrm{SH}_{1}\right.$ and $\left.\mathrm{SH}_{2}\right)$, integrated subsurface hardness $(\triangle \mathrm{KHN})$ and fluoride concentration in enamel $\left(\mu \mathrm{g} / \mathrm{mm}^{3}\right.$ ) were considered as the response variables. The project was reviewed and approved by the Research Ethics Committee of Univ. Estadual Paulista (UNESP), Brazil (\#2007/02270).

\section{Dentifrice formulation and fluoride assessment \\ Dentifrices used in the study were produced} in the laboratory of Pediatric Dentistry of Araçatuba Dental School (UNESP, Brazil) contained the following components: titanium dioxide, carboxymethylcellulose, methyl-phydroxybenzoate, sodium saccharin, peppermint oil, glycerol, hydrated silica, sodium lauryl sulfate, and water. Sodium fluoride (NaF, Merck ${ }^{\circledR}$, Darmstadt, Germany) was added to the formulations in order to obtain the concentrations of 275, 550 and 1,100 $\mu \mathrm{g} / \mathrm{g}$. A dentifrice without fluoride (placebo) was also prepared.

Total fluoride (TF) and ionic fluoride (IF) were assessed according to Delbem, et al. ${ }^{10}$ (2002), using an F ion-specific electrode (Orion 9609 BN; Orion Research Inc, Beverly, MA, USA) coupled to an ion analyzer (Orion $720 \mathrm{~A}^{+}$; Orion Research Inc, Beverly, MA, USA), previously calibrated with five standard solutions $(0.125,0.25,0.5,1.0$, and 2.0 $\mu \mathrm{g} / \mathrm{mL})$.

\section{Volunteer selection}

Twelve young adults, aged $20-30$ years, living in an area with fluoridated drinking water (0.7 $\mathrm{mg} F / L$ ) were randomly selected, with no gender distinction. As inclusion criteria, volunteers should present good general and oral health and normal salivary flow rate ${ }^{11}$. Exclusion criteria included the use of any medicine likely to interfere with salivary secretion, use of fixed or removable orthodontic appliances, pregnancy or breastfeeding, smoking, or presence of any systemic illness. Volunteers who showed average mineral gain higher than $20 \%$ using placebo dentifrice (3-day experimental regimen) were also excluded $(n=2)$.

\section{Enamel blocks preparation and subsurface demineralization \\ Enamel blocks $(3 \times 3 \mathrm{~mm}, n=330)$ were obtained} from bovine incisors, sequentially polished (200 $\mu \mathrm{m})$ and selected by surface hardness $(\mathrm{SH})$. Artificial subsurface demineralization was produced according to Queiroz, et al. ${ }^{21}$ (2008) as modified by Spiguel, et al. ${ }^{23}$ (2009). Selected blocks were isolated with acid-resistant varnish, except for the enamel surface $\left(9 \mathrm{~mm}^{2}\right)$, and immersed individually in demineralizing solution $\left(1.3 \mathrm{mmol} . \mathrm{L}^{-1} \mathrm{Ca}, 0.78\right.$ mmol. $\mathrm{L}^{-1} \mathrm{P}$ in $0.05 \mathrm{~mol} . \mathrm{L}^{-1}$ acetate buffer $[\mathrm{pH} 5.0]$; 0.03 ppm F; $18 \mathrm{~mL} /$ block) for 16 hours, at $37^{\circ} \mathrm{C}$. Blocks were then submitted to post demineralization 
surface hardness $\left(\mathrm{SH}_{1}\right)$.

\section{In situ study protocol and instructions to volunteers}

Volunteers were given information on the study protocol and signed a written, informed consent prior to the beginning of the study. Palatal appliances should be used all the time during each experimental phase (including during sleep), and should be removed only during the main meals. The participants were also instructed not to use any fluoride products (except fluoridated drinking water) and/or antibacterial mouthwashes.

Custom-made acrylic palatal appliances were provided to the volunteers ${ }^{11}$, which included 4 demineralized enamel blocks (two on each side), fixed on the same level of the appliance in order to minimize plaque accumulation. Each experimental dentifrice was tested separately for 3 and 7 days, totaling 8 experimental phases. Volunteers were instructed to brush their natural teeth and the palatal appliances (including the enamel blocks), three times per day, for 1 minute each time, and to rinse their mouth with tap water. One week before the beginning of the experiment and between treatments, volunteers used a fluoride-free dentifrice (wash-out).

\section{Analysis of enamel hardness}

Surface and cross-sectional enamel hardness was measured using a Shimadzu HMV-2000 hardness tester (Knoop diamond, $25 \mathrm{~g}, 10 \mathrm{~s}$, HMV-2000; Shimadzu Corporation, Tokyo, Japan) coupled to CAMS-WIN software (Newage Testing Instruments, Southampton, PA, USA). Five impressions were performed in the central region of each block, $100 \mu \mathrm{m}$ distant from each other $(\mathrm{SH})$. After artificial enamel demineralization $\left(\mathrm{SH}_{1}\right)$ and after the in situ experimental remineralization $\left(\mathrm{SH}_{2}\right)$, five impressions $100 \mu \mathrm{m}$ distant from each other and from the initial impressions $(\mathrm{SH})$ were performed ${ }^{26}$.

Blocks were then longitudinally sectioned into two halves through the central part of the exposed enamel. One half was embedded in acrylic resin and sequentially polished. For cross-sectional hardness measurements, 3 sequences of 8 impressions were performed at distances 10, 30, 50, 70, 90, 110, 220, and $330 \mu \mathrm{m}$ from the external surface of enamel; one sequence was performed in the central region of the block and the other two sequences were done on each side $(100 \mu \mathrm{m})$ of the first sequence. The mean of the three measurements was calculated for each distance. The integrated area under the curve (cross-sectional hardness profiles into the enamel), using hardness values (KHN), was calculated by the trapezoidal rule (GraphPad Prism, version 3.02, San Diego, CA, USA) for each depth $(\mu \mathrm{m})$ from the lesion to sound enamel. This value was subtracted from the integrated area of sound enamel to obtain the integrated area of subsurface regions in enamel, which was named integrated loss of subsurface hardness $(\mathrm{DKHN})^{23}$.

\section{Lesion depth analysis}

Sections of $600 \mu \mathrm{m}$ thick were obtained from demineralized blocks not submitted to the in situ protocol ( $n=10$, control) using a diamond disk, and subsequently ground and polished (Phoenix BetaVector; Buehler, Lake Bluff, IL, USA) resulting in slices $100 \mu \mathrm{m}$ thick. Enamel sections were mounted on slides in deionized/distilled water, covered with a coverslip and sealed with ethelan resin. Sections were then examined by polarized light microscopy (Axiophot; Zeiss DSM-940 A, Oberkochen, Germany) at 400x magnification. Three areas in the central region of the slices were analyzed to verify the presence and thickness of the superficial enamel layer and to assess demineralization depth $(\mu \mathrm{m})$, using Axiovision Software Rel. 4.3. The same procedure was done for each group (3 blocks/ group), on the embedded enamel halves used for the cross-sectional hardness analysis.

\section{Determination of fluoride in enamel}

Enamel biopsy was performed based on the study by Weatherell, et al. ${ }^{28}(1985)$ as modified by Alves, et al. ${ }^{2}$ (2007). Enamel blocks $(1.5 \times 1.5$ $\mathrm{mm}$ ) were obtained from the halves not embedded for cross-sectional analysis, fixed to a handpiece mandrel, coupled to a microscope attached to a digital micrometer (Pantec, São Paulo, SP, Brazil) so that biopsy depth could be measured. Selfadhesive polishing discs (13 $\mathrm{mm}$ in diameter), 400 grit silicon carbide paper (Buehler Ltd, Lake Bluff, IL, USA) were fixed to the bottom of polystyrene crystal tubes (J-10, Injeplast, São Paulo, SP, Brazil), to remove a $50 \mu \mathrm{m}$ enamel layer. To each tube,

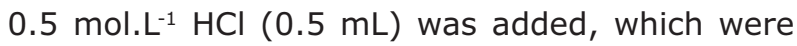
constantly shaken for 30 minutes. Following, 0.5 mol. $\mathrm{L}^{-1} \mathrm{NaOH}(0.5 \mathrm{~mL})$ was added ${ }^{2}$.

Samples were buffered with TISAB III (Orion Research Inc, Beverly, MA, USA) and fluoride was analyzed using a fluoride ion-selective electrode (9409, Orion Research Inc, Beverly, MA, USA) and a reference microelectrode (Analyser, São Paulo, SP, Brazil), both connected to an ion analyzer (Orion $720 \mathrm{~A}^{+}$). Five standard solutions ( 0.045 to $0.720 \mu \mathrm{g}$ $\mathrm{F} / \mathrm{mL}$ ), containing $\mathrm{HCl}, \mathrm{NaOH}$ and TISAB III at the same ratios as the samples were used to calibrate the electrode. The results are expressed as $\mu \mathrm{g} / \mathrm{mm}^{3}$.

\section{Statistical analysis}

Statistical analysis was performed using GMC software version $2002^{6}$, with a significance level of $5 \%$. Experimental dentifrices and regimen periods 
( 3 and 7 days) were considered as variation factors, and values of $\mathrm{SH}, \mathrm{SH}_{1}, \mathrm{SH}_{2}, \Delta \mathrm{KHN}$, and enamel fluoride concentration were considered as variables. Data passed normality (Kolmogorov-Smirnov) and homocedasticity (Cochran) tests, and were submitted to 2-way ANOVA, followed by Tukey's test. The relationships between enamel fluoride concentrations and $\mathrm{SH}_{2}$ and $\triangle \mathrm{KHN}$ were verified by Pearson's correlation coefficient. Post hoc power analysis was calculated for $\mathrm{SH}_{2}$ and $\Delta \mathrm{KHN}$ between groups that did not reach significant differences.

\section{RESULTS}

Total and ionic fluoride concentrations (SD, $n=3)$ in the experimental dentifrices were $8.2(0.7)$ and $5.5(0.2) ; 263.9$ (3.6) and 280.1 (3.6); $544.3(8.2)$ and 567.2 (7.6); $1,129.6$ (15.4) and 1,150.4 (6.9) $\mu \mathrm{g} \mathrm{F} / \mathrm{g}$, respectively for the placebo, 275,550 , and $1,100 \mu \mathrm{g} \mathrm{F} / \mathrm{g}$ dentifrices. Mean (SD) initial surface hardness (SH) for all blocks was $362.5(4.2) \mathrm{Kg} /$ $\mathrm{mm}^{2}$, ranging from $359.7(3.2)$ to $366.2(4.2) \mathrm{Kg} /$ $\mathrm{mm}^{2}$ in the experimental groups $(p=0.492)$. Mean (SD) post demineralization surface hardness $\left(\mathrm{SH}_{1}\right)$ was $74.8(13.4) \mathrm{Kg} / \mathrm{mm}^{2}$ for all blocks, ranging from $66.0(12.5)$ to $82.5(9.0) \mathrm{Kg} / \mathrm{mm}^{2}$ in the experimental groups $(p=0.344)$.

Enamel blocks analyzed by polarized light microscopy presented a superficial enamel layer followed by an area of extreme demineralization, as shown in Figure 1. Mean demineralization depth (SD) was 47.7 (12.6) $\mu \mathrm{m}$, ranging from 36.5 to 66.5 $\mu \mathrm{m}$. The superficial enamel layer thickness (SD) was $9.8(0.9) \mu \mathrm{m}$, ranging from 8.3 to $10.8 \mu \mathrm{m}$. Figure 1 also shows decreased demineralized areas with increased fluoride concentration in the dentifrices and increased duration of the experimental protocol.

Ten volunteers completed the study; two subjects were excluded from the experiment, as they presented average mineral gain higher than $20 \%$ using placebo dentifrice. A dose-response relationship was observed between fluoride concentrations in the dentifrice and surface hardness $\left(\mathrm{SH}_{2}\right)$, as shown in Figure $2 \mathrm{~A}$. For the 3-day experimental period, all experimental groups showed statistically significant differences among each other. For the 7-day period, no significant differences were observed between groups treated with dentifrices containing 0 and 275 (power $=0.93$, $\mathrm{p}=0.164) ; 275$ and 550 (power $=0.86, \mathrm{p}=0.06)$; and 550 and $1,100 \mu \mathrm{g} \mathrm{F} / \mathrm{g}$ (power=0.88, $\mathrm{p}=0.413$ ). When both treatment periods were compared, only the 3-day placebo group was statistically different from all other groups $(p=0.004)$. No significant differences were observed among the 7-day placebo group and 3- and 7-day $275 \mu \mathrm{g} / \mathrm{F}$ groups $(p=0.08)$; or 7 -day $275 \mu \mathrm{g} \mathrm{F} / \mathrm{g}$, 3-day $550 \mu \mathrm{g} \mathrm{F} / \mathrm{g}$ and 7 -day $550 \mu \mathrm{g} \mathrm{F} / \mathrm{g}$ groups $(p=0.137)$. Blocks treated with the $1,100 \mu \mathrm{g} \mathrm{F} / \mathrm{g}$ dentifrices were not significantly different for the 3- and 7-day periods $(p=0.821)$, which showed statistically similar values to the 7 -day $550 \mu \mathrm{g} \mathrm{F/g}$ group ( $\mathrm{p}=0.257, \mathrm{p}=0.226$, respectively).

An inverse relationship was observed between
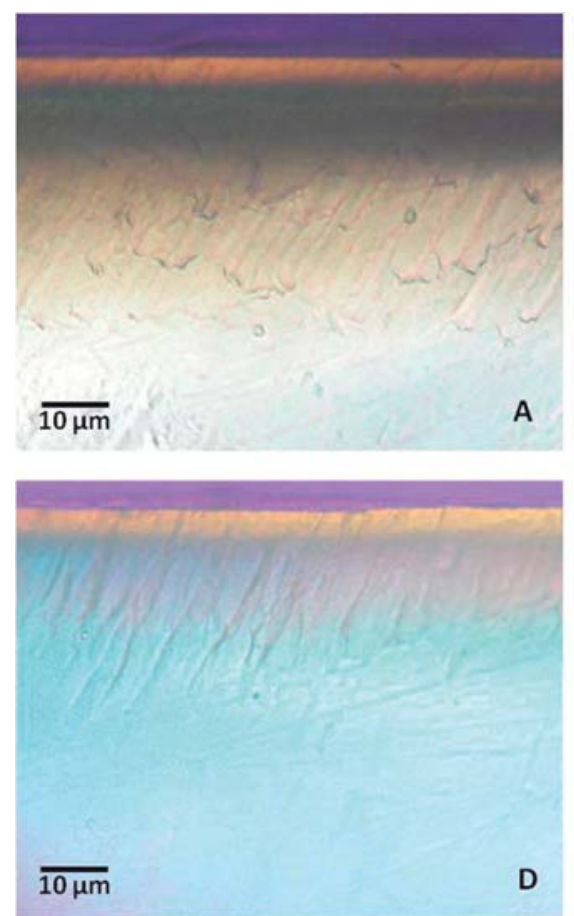
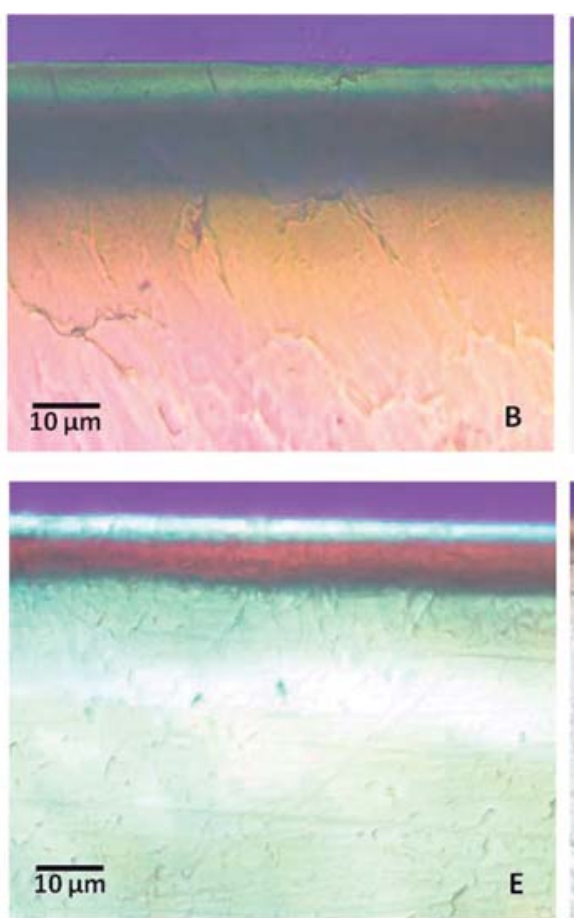
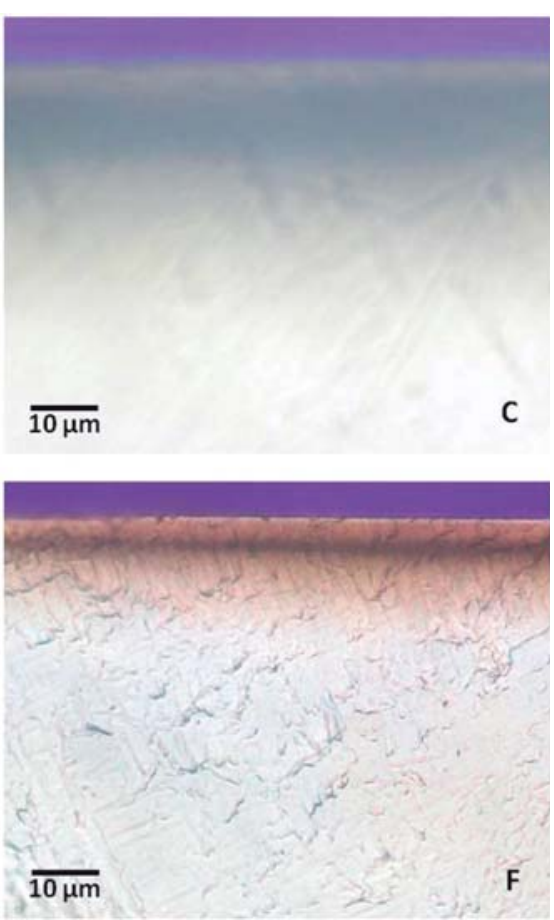

Figure 1- Polarized light photomicrographs of lesions formed after subsurface demineralization prior to the beginning of the experiment $(A)$, and after in situ treatment with the following dentifrices and experimental periods: placebo, 3-day (B); placebo, 7-day (C); $275 \mu \mathrm{g} \mathrm{F/g} \mathrm{7-day} \mathrm{(D);} 500 \mu \mathrm{g} \mathrm{F/g} \mathrm{7-day} \mathrm{(E);} \mathrm{and} \mathrm{1,100} \mathrm{\mu g} \mathrm{F/g} \mathrm{7-day} \mathrm{(F).} \mathrm{Images} \mathrm{at} \mathrm{400x} \mathrm{magnification}$ 


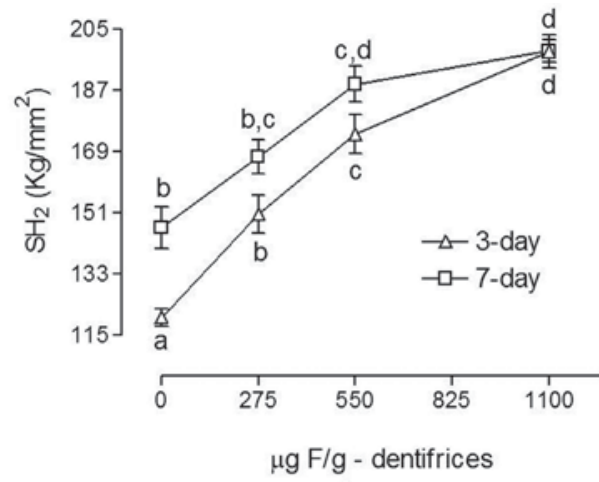

A
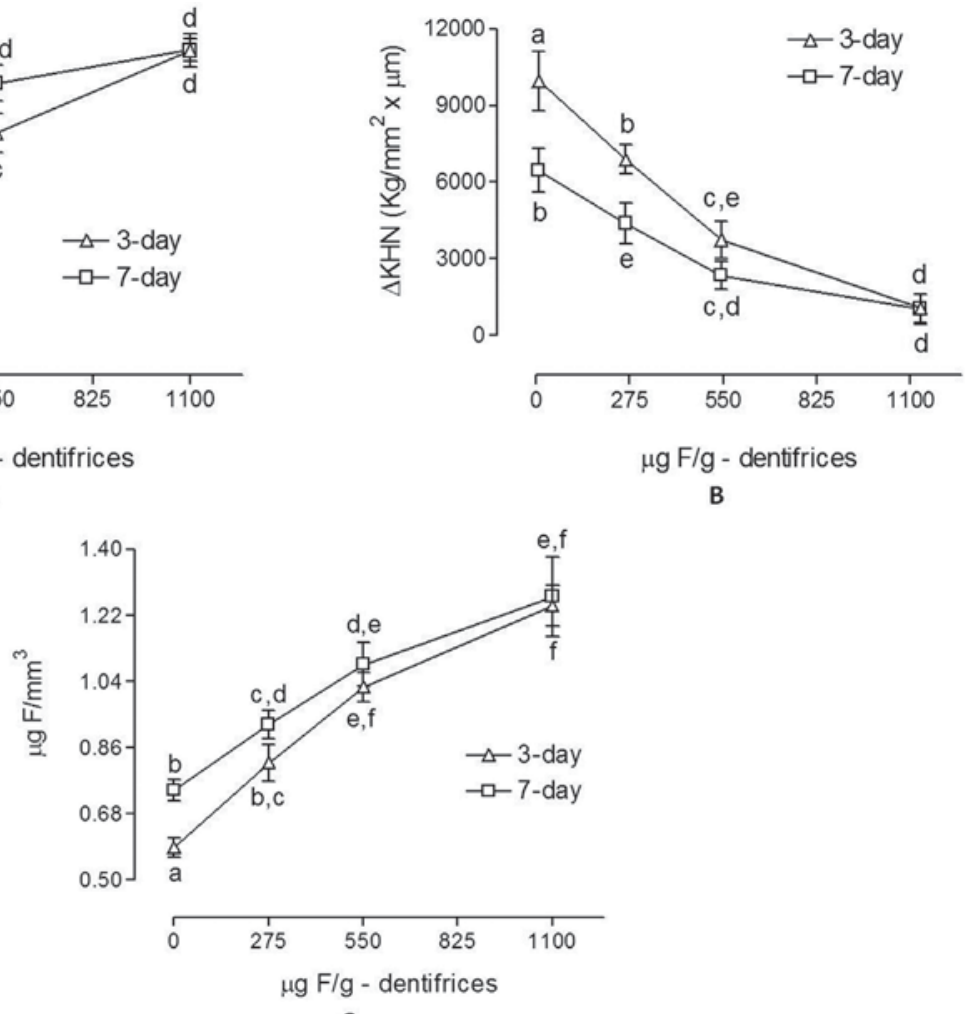

$\mathrm{C}$

Figure 2- Mean surface hardness (A), integrated subsurface hardness (B) and enamel fluoride concentrations (C) according to fluoride concentration in dentifrices and treatment regimens ( 3 and 7 days). Values within parentheses in A indicate percentage of surface hardness recovery. Different letters indicate statistically significant differences (2-way ANOVA, followed by Tukey's test, $p<0.05)$. Bars indicate standard errors $(n=10)$

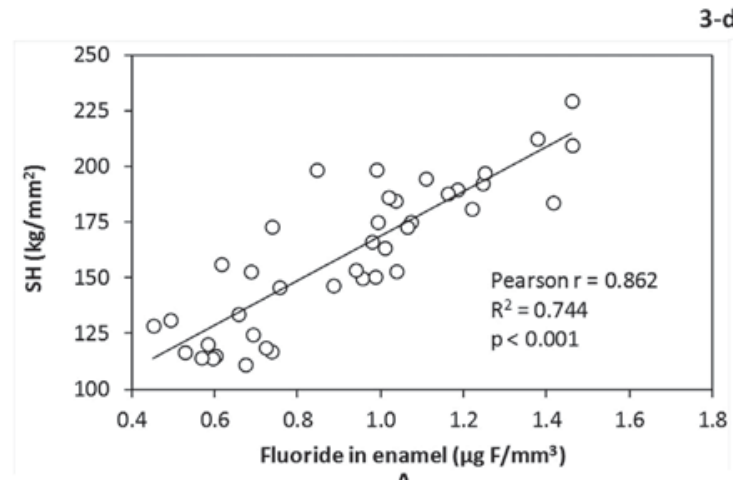

A

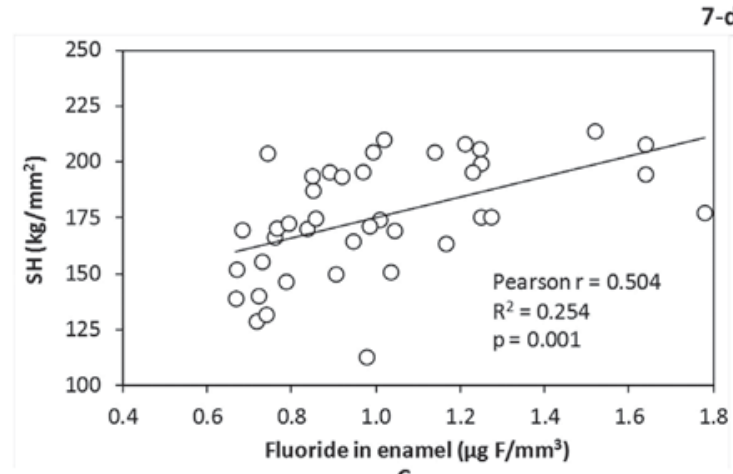

C

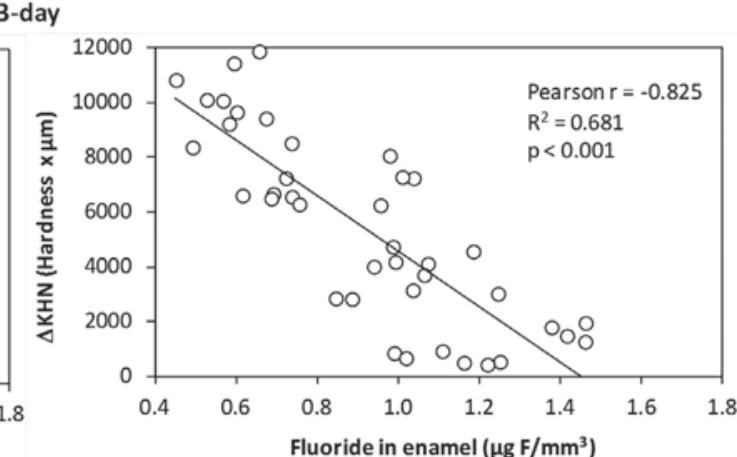

B

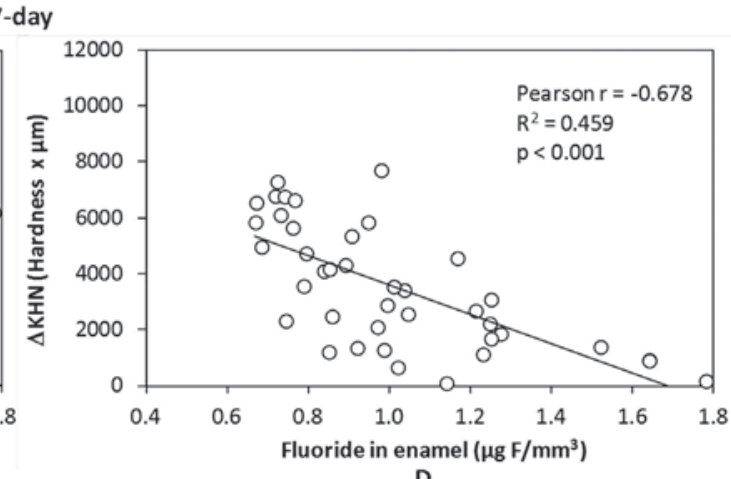

D

Figure 3- Relationships between enamel fluoride concentration and surface hardness ( $A$ and $C$ ) and integrated subsurface hardness $(B$ and $D)$, respectively for the 3- and 7-day experimental protocols. Pearson's correlation coefficient $(p<0.05)$ 
fluoride concentrations in the dentifrices and the integrated subsurface hardness $(\Delta \mathrm{KHN})$, as shown in Figure 2B. As for $\mathrm{SH}_{2}$, significant differences were observed among all groups for the 3-day period $(p<0.001)$. For the 7-day period, no significant differences were observed for the 550 and 1,100 $\mu \mathrm{g} F / \mathrm{g}$ groups (power $=1.00, \mathrm{p}=0.181$ ). Comparing both treatment periods, statistically similar values were seen between 7-day placebo and 7-day $275 \mu \mathrm{g}$ $\mathrm{F} / \mathrm{g}$ groups $(\mathrm{p}=0.128), 7$-day $275 \mu \mathrm{g} / \mathrm{g}$ and 3-day $550 \mu \mathrm{g} / \mathrm{g}$ groups $(p=0.593)$, as well as among 3- and 7-day 1,100 $\mu \mathrm{g} \mathrm{F/g}$ and 7-day 550- $\mu \mathrm{g} \mathrm{F/g}$ groups $(p=0.184, p=0.181$, respectively).

A dose-response relationship was verified between fluoride concentrations in the dentifrices and in enamel (Figure 2C). For the 3-day treatment groups, significant differences were observed among all groups $(p=0.03)$, except between groups treated with 550 and $1,100 \mu \mathrm{g} / \mathrm{g}$ dentifrices $(p=0.127)$. For the 7 -day period, no significant differences were observed between the 275 and the $550 \mu \mathrm{g} / \mathrm{g}$ groups $(p=0.132)$, or between the 550 and the $1,100 \mu \mathrm{g} / \mathrm{g}$ groups $(p=0.613)$. When comparing both treatment periods, similar results were observed between the 7-day placebo and 3-day $275 \mu \mathrm{g} / \mathrm{g}$ groups $(p=0.430)$, as well as between 3- and 7-day $275 \mu \mathrm{g} / \mathrm{g}$ groups $(p=0.303)$. No significant differences were observed among 3- and 7-day groups treated with 550 and $1,100 \mu \mathrm{g} \mathrm{F} / \mathrm{g}$ dentifrices $(p=0.101)$.

Enamel fluoride concentration was positive and significantly correlated with $\mathrm{SH}_{2}$ and $\Delta \mathrm{KHN}$ (Figure 3). Higher correlation coefficients were observed for the 3-day experimental protocol (A and B) when compared to the 7-day protocol ( $C$ and $D$ ), for both variables.

\section{DISCUSSION}

The supersaturation of saliva with respect to the dental mineral indicates that enamel remineralization naturally occurs when salivary $\mathrm{pH}$ is above 5.5, and even traces of fluoride make saliva highly supersaturated with respect to fluorhydroxyapatite ${ }^{5}$. Therefore, in situ protocols assessing the remineralizing effects of fluoridated products should allow for the remineralization process to occur by the action of saliva when associated to a placebo treatment, indicating that it primarily occurs through the effects of intraoral calcium and phosphate ions. Some in situ models have shown mineral loss after a placebo treatment, thereby hindering observation of the effects of salivary ions in the process ${ }^{8}$. Other protocols have not included a placebo group, making it impossible to verify whether the resulting effects were due to the salivary action or the treatment itself ${ }^{16}$. The present 3-day experimental model, on the other hand, promoted a mineral gain of $18.4 \%$ in the placebo group when compared to baseline values. This result was 1.5 times higher $(28.2 \%)$ when the same dentifrice was used for 7 days, indicating that the protocol fulfilled the above-mentioned requirement.

In the present study, only volunteers with mineral gain lower than $20 \%$ after using a placebo dentifrice for a 3-day period were selected. This selection criterion was adopted so that the capacity of fluoride products in enhancing remineralization in difficult situations (by enrolling less responsive subjects) could be evaluated, besides minimizing variability among volunteers. When a remineralizing agent is used in the clinical situation, it is expected that its action occurs within the shortest length of time possible. However, as in vivo demineralization and remineralization processes depend on multiple factors $^{5}$, the accurate determination of the length of time for in situ protocols becomes a difficult task. In this sense, some important variables should be considered before determining the experimental period of an in situ study. Among these factors, the type of substrate and the depth of the artificial caries lesion seem to be the most important.

Bovine enamel has a higher reactivity and porosity, which leads to faster remineralization when compared to human enamel ${ }^{12,13,18}$. It has been shown that human enamel remineralization in situ was accomplished in nine days, exhibiting a higher remineralization rate on the first days ${ }^{14,16}$. In the present study, the demineralized areas associated to the use of the $1,100 \mu \mathrm{g} \mathrm{F} / \mathrm{g}$ dentifrice were 9.4 and 3.5 times lower than those verified after using the placebo and the $550 \mu \mathrm{g} \mathrm{F/g}$ dentifrices, respectively, in the 3-day experimental model. For the 7-day experimental period, an increase in mineral gain around $30 \%$ was observed for the placebo group, whereas no changes were verified after using the $1,100 \mu \mathrm{g} / \mathrm{g}$ dentifrice, in comparison to groups treated with the same dentifrices for 3 days. Moreover, the remineralization results $\left(\mathrm{SH}_{2}\right.$ and $\triangle \mathrm{KHN}$ ) were directly related to enamel fluoride concentrations, but longer exposure to fluoridecontaining dentifrice did not increase fluoride concentration in enamel. Also, the correlation coefficients observed between enamel fluoride concentrations and $\mathrm{SH}_{2}$ and $\Delta \mathrm{KHN}$ were higher for the 3-day experimental protocol when compared to 7-day one. Taking the considerations above into account, it becomes clear that longer experimental designs may reduce the model capacity to verify fluoride dose-response effects. This is particularly critical in study protocols using 14- to 60-day experimental periods ${ }^{1,4,7-9,16,19,22,25}$.

As for the substrate, the depth of enamel demineralization may also interfere with remineralization time; however, few studies have 
considered the depth of the demineralized area in their protocols, which ranged from 30.0 to 77.3 $\mu \mathrm{m}^{4,16}$. The mean depth of artificial demineralization in the present study was $47.7 \mu \mathrm{m}$, resembling a subsurface lesion (Figure $1 \mathrm{~A}$ ). It is known that the remineralization process is slower in deep lesions $( \pm 100 \mu \mathrm{m})$ due to a longer distance for ion diffusion when compared to that seen in the present study ${ }^{20}$. The present results indicate that the peak remineralization capacity of the $1,100 \mu \mathrm{g}$ $\mathrm{F} / \mathrm{g}$ dentifrice was achieved in only 3 days, with no significant difference between the results obtained 7 days after using the same dentifrice. Considering that the placebo, 275 and $550 \mu \mathrm{g} \mathrm{F} / \mathrm{g}$ dentifrices tested for 7 days achieved $\mathrm{SH}_{2}$ and $\triangle \mathrm{KHN}$ values similar to those found for the 275, 550 and 1,100 $\mu \mathrm{g} \mathrm{F/g}$ dentifrice, respectively, it can be assumed that all treatment groups could achieve the same values as those obtained for the $1,100 \mu \mathrm{g} \mathrm{F} / \mathrm{g}$ dentifrice had the experimental protocol been longer. This assumption is also supported by the analysis of the polarized light microscopy images, which show a clear reduction in the demineralized areas influenced by both the fluoride concentration in dentifrices and the time of the experimental protocol. Therefore, according to the present protocol, longer experimental periods would not allow for the assessment of the actual effects of the fluoride concentrations in the dentifrices.

Another factor allowing for fast remineralization in the 3-day protocol, after using the 1,100 $\mu \mathrm{g} \mathrm{F/g}$ dentifrice was the type of lesion. Figure $1 \mathrm{~A}$ shows a demineralized area under a more mineralized surface zone (red) than the lesion body (deeper zone); the surface zone, however, is extremely less mineralized than sound enamel (yellow). This type of lesion presents a faster remineralization rate due to the higher number and diameter of the lesion pores, being suitable for comparing the efficacy of different remineralizing regimens ${ }^{17}$.

\section{CONCLUSIONS}

In summary, it can be concluded that the present in situ remineralization model was able to verify dose-response effects with both 3- and 7-day experimental periods. However, as the 3-day protocol resulted in higher correlation coefficients between fluoride concentration in the dentifrice and $\mathrm{SH}_{2}$ and $\Delta \mathrm{KHN}$, and considering that the peak remineralization capacity of the conventional dentifrice formulation $(1,100 \mu \mathrm{g} \mathrm{F} / \mathrm{g})$ was achieved in 3 days, this experimental period could be used in future studies assessing the effects of new dentifrice formulations, especially at low-fluoride concentrations. It is important to highlight that in addition to the ability to determine dose-response effects, this short-term experimental design may lead to better volunteer compliance, which would result in more reliable and standardized results.

\section{REFERENCES}

1- Altenburger MJ, Schirrmeister JF, Wrbas KT, Klasser M, Hellwig $\mathrm{E}$. Fluoride uptake and remineralization of enamel lesions after weekly application of differently concentrated fluoride gels. Caries Res. 2008;42:312-8.

2- Alves KM, Pessan JP, Brighenti FL, Franco KS, Oliveira FA, Buzalaf MA, et al. In vitro evaluation of effectiveness of acidic fluoride dentifrices. Caries Res. 2007;41:263-7.

3- Ammari AB, Bloch-Zupan A, Ashley PF. Systematic review of studies comparing the anti-caries efficacy of children's toothpaste containing $600 \mathrm{ppm}$ of fluoride or less with high fluoride toothpastes of 1,000 ppm or above. Caries Res. 2003;37:85-92. 4- Buchalla W, Attin T, Schulte-Mönting J, Hellwig E. Fluoride uptake, retention, and remineralization efficacy of a highly concentrated fluoride solution on enamel lesions in situ. J Dent Res. 2002;81:329-33.

5- Buzalaf MA, Pessan JP, Honório HM, ten Cate JM. Mechanisms of action of fluoride for caries control. Monogr Oral Sci. 2011;22:97114.

6- Campos GM. GMC 2002 [software]; 2003. Available from: http://www.forp.usp.br/restauradora/gmc/gmc.html\#gmc.

7- Chow LC, Takagi S, Carey CM, Sieck BA. Remineralization effects of a two-solution fluoride mouthrinse: an in situ study. J Dent Res. 2000;79:991-5.

8- Cochrane NJ, Shen P, Byrne SJ, Walker GD, Adams GG, Yuan $Y$, et al. Remineralisation by chewing sugar-free gums in a randomised, controlled in situ trial including dietary intake and gauze to promote plaque formation. Caries Res. 2012;46:147-55. 9- Cury JA, Hashizume LN, Del Bel Cury AA, Tabchoury CP. Effect of dentifrice containing fluoride and/or baking soda on enamel demineralization/remineralization: an in situ study. Caries Res. 2001;35:106-10.

10- Delbem AC, Bergamaschi M, Rodrigues E, Sassaki KT, Vieira $A E$, Missel EM. Anticaries effect of dentifrices with calcium citrate and sodium trimetaphosphate. J Appl Oral Sci. 2012;20:94-8.

11- Delbem AC, Danelon M, Sassaki KT, Vieira AEM, Takeshita $E M$, Brighenti $F L$, et al. Effect of rinsing with water immediately after neutral gel and foam fluoride topical application on enamel remineralization: an in situ study. Arch Oral Biol. 2010;55:913-8. 12- Edmunds DH, Whittaker DK, Green RM. Suitability of human, bovine, equine, and ovine tooth enamel for studies of artificial bacterial carious lesions. Caries Res. 1988;22:327-36.

13- Featherstone JD, Mellberg JR. Relative rates of progress of artificial carious lesions in bovine, ovine and human enamel. Caries Res. $1981 ; 15: 109-14$

14- Goorhuis J, Purdell-Lewis DJ. 0.25\% and $0.4 \%$ amine fluoride gel for weekly topical application. An in vivo study on human dental enamel. Caries Res. 1986;20:458-64.

15- Horowitz HS. The need for toothpastes with lower than conventional fluoride concentrations for preschool-aged children. J Public Health Dent. 1992;52:216-21.

16- Lagerweij MD, ten Cate JM. Remineralisation of enamel lesions with daily applications of a high-concentration fluoride gel and a fluoridated toothpaste: an in situ study. Caries Res. 2002;36:270-4.

17- Lynch RJ, Mony U, ten Cate JM. Effect of lesion characteristics and mineralizing solution type on enamel remineralization in vitro. Caries Res. 2007;41:257-62.

18- Lynch RJ, ten Cate JM. The effect of lesion characteristics at baseline on subsequent de- and remineralization behaviour. Caries Res. 2006;40:530-5. 
19- Magalhães AC, Furlani TA, Italiani FM, Iano FG, Delbem AC, Buzalaf MA. Effect of calcium pre-rinse and fluoride dentifrice on remineralisation of artificially demineralised enamel and on the composition of the dental biofilm formed in situ. Arch Oral Biol. 2007;52:1155-60.

20- Mellberg JR. Relationship of original mineral loss in caries-like lesions to mineral changes in situ. Caries Res. 1991;25:459-61. 21- Queiroz CS, Hara AT, Paes Leme AF, Cury JA. pH-cycling models to evaluate the effect of low fluoride dentifrice on enamel de- and remineralization. Braz Dent J. 2008;19:21-7.

22- Reynolds EC, Cai F, Cochrane NJ, Shen P, Walker GD, Morgan $M V$, et al. Fluoride and casein phosphopeptide-amorphous calcium phosphate. J Dent Res. 2008;87:344-8.

23- Spiguel MH, Tovo MF, Kramer PF, Franco KS, Alves KM, Delbem AC. Evaluation of laser fluorescence in the monitoring of the initial stage of the de-/remineralization process: an in vitro and in situ study. Caries Res. 2009;43:302-7.

24- Stookey GK, Mau MS, Isaacs RL, Gonzales-Gierbolini C, Bartizek RD, Biesbrock AR. The relative anticaries effectiveness of three fluoride-containing dentifrices in Puerto Rico. Caries Res. 2004;38:542-50.
25- Takeshita EM, Exterkate RA, Delbem AC, ten Cate JM. Evaluation of different fluoride concentrations supplemented with trimetaphosphate on enamel de- and remineralization in vitro. Caries Res. 2011;45:494-7.

26- Vieira AE, Delbem AC, Sassaki KT, Rodrigues E, Cury JA, Cunha RF. Fluoride dose response in $\mathrm{pH}$-cycling models using bovine enamel. Caries Res. 2005;39:514-20.

27- Walsh T, Worthington HV, Glenny AM, Appelbe P, Marinho VC, Shi X. Fluoride toothpastes with different concentrations for preventing dental caries in children and adolescents. Cochrane Database Syst Rev. 2010;20:CD007868.

28- Weatherell JA, Robinson C, Strong M, Nakagaki H. Microsampling by abrasion. Caries Res. 1985;19:97-102.

29- Wong MC, Clarkson J, Glenny AM, Lo EC, Marinho VC, Tsang BW, et al. Cochrane reviews on the benefits/risks of fluoride toothpastes. J Dent Res. 2011;90:573-9. 